\title{
A forced-choice adaptive procedure for measuring auditory thresholds in children
}

\author{
WILLIAM A. YOST \\ Parmly Hearing Institute, Loyola University, Chicago, Illinois 60626
}

\begin{abstract}
A modification of the two-down/one-up tracking procedure was used to estimate thresholds of audibility in 46 children (ages 3 to 6 years) and 10 adults. A two-alternative forced-choice version (26 children, 5 adults) of this method was successful in estimating thresholds of audibility in 5-year-olds, but not in 3- and 4-year-olds. A single-interval version of the procedure was successful in estimating thresholds of audibility for all the children. Measures from the children of between- and within-subjects variability, psychometric functions, and response bias all indicate that the procedure enables one to estimate thresholds that are in close agreement with those obtained from adults and with results of other investigators.
\end{abstract}

For experimental as well as for clinical reasons, a procedure is needed that allows accurate estimates of thresholds of audibility in children. Most laboratory psychophysical procedures are too demanding in terms of time and subject responsibility to be used with children. Most methods of obtaining thresholds from children in the clinic do not allow for a high degree of accuracy in the estimation of thresholds (Watson, Franks, \& Hood, 1972).

In recent years, adaptive psychophysical methods have allowed for relatively quick and accurate determinations of thresholds (Levitt, 1971; Taylor \& Creelman, 1967). These methods are simple to administer and use instructions that children understand.

Levitt (1971) describes a form of the adaptive procedure called up-down tracking. In this procedure, two observation intervals are presented per trial and the signal occurs in either the first or second observation interval. The subject's task is to indicate which interval contains the signal. This is a two-alternative forcedchoice task (2AFC). Intensity is lowered following some number of correct responses (the subject correctly identifies the interval containing the signal), and signal intensity is increased following some number of incorrect responses (the subject identifies an interval as having a signal when the signal is not present). One rule frequently used is to lower signal intensity after the subject makes two correct responses in a row, and to raise signal intensity by the same amount after the subject makes an incorrect response (i.e., the twodown/one-up adaptive psychophysical procedure). As this experiment continues, the subject's behavior results in a condition in which the intensity is as likely to increase as it is to decrease. At this point, Levitt (1971)

This research was supported by National Institute of Health Contract NOINS-5-2313, while the author was at the University of Florida. The author would like to thank the other investigators on the contract, Donald Teas, Keith Berg, and Kathy Berg, as well as the computer programmer, Jamie Stone. has shown that the average intensity of the signal should yield $70.7 \%$ correct if it is presented in a nonadaptive 2AFC task. Some investigators have found that, after 50 to 100 trials, the average intensity of the stimulus yields $71 \%$ correct (see Jesteadt, Weir, \& Green, 1977). Others compute the intensity of the stimulus after the intensity has gone through 8 to 12 reversals (see Yost, 1975). This asymptotic intensity then becomes an estimate of the threshold for any one condition.

Since the two-down/one-up adaptive procedure is one of the easiest adaptive procedures to use, we investigated its use as a procedure for measuring absolute auditory threshold with children aged 3 to 6 years.

\section{EXPERIMENT 1A}

\section{Method}

Subjects. The 20 children tested ranged in age from 3 years 0 months to 5 years 2 months. We tested 10 3-year-olds, 5 4-year-olds, 5 5-year-olds, and, as a type of control, 5 adults. All subjects (or their parents) reported no known hearing abnormalities.

Stimuli. The stimuli were $1-\sec$ tone bursts shaped with 10 -msec rise-decay times. Frequencies of $250,500,2,000,4,000$, and $8,000 \mathrm{~Hz}$ were tested once and $1,000 \mathrm{~Hz}$ was tested three times.

Procedure. A large ( $1 \mathrm{ft} \times 8 \mathrm{in}$.) response box with two response keys (each $3 \times 5$ in.) was used to obtain the responses. The response keys were lit during the observation interval: The left key was lit during Observation Interval 1 and the right key during Observation Interval 2. After determining the patterns, numbers, or letters that a child could clearly differentiate, these were placed in the response keys. The child was then told to listen (the tones were always presented to the right ear through TDH-39 headphones) and to decide if he or she heard a sound when the first key, perhaps illuminating a cow figure, or the second key, perhaps a horse figure, was lit. The child was instructed to push the key associated with the sound. The level of the tone began at $60 \mathrm{dBSPL}{ }^{1}$ for the 250 and $8,000-\mathrm{Hz}$ tones and at $40 \mathrm{~dB}$ SPL for other frequencies. The beginning level $(60 \mathrm{~dB}$ SPL) decreased by $8 \mathrm{~dB}$ following every two successive correct responses. After the first incorrect response, the level was decreased by $4 \mathrm{~dB}$ after every two successive correct responses and increased by $4 \mathrm{~dB}$ after any incorrect 
Table 1

Table of Thresholds in Decibels SPL Required to Obtain Thresholds for 3-, 4-, and 5-Year-Olds and for Adults, Using the Adaptive Psychophysical Procedure

\begin{tabular}{|c|c|c|c|c|c|c|c|c|c|c|}
\hline \multirow[b]{2}{*}{ Subject } & \multicolumn{2}{|c|}{ Age } & \multicolumn{3}{|c|}{$1,000 \mathrm{~Hz}$} & \multirow[b]{2}{*}{$250 \mathrm{~Hz}$} & \multirow[b]{2}{*}{$500 \mathrm{~Hz}$} & \multirow[b]{2}{*}{$2,000 \mathrm{~Hz}$} & \multirow[b]{2}{*}{$4,000 \mathrm{~Hz}$} & \multirow[b]{2}{*}{$8,000 \mathrm{~Hz}$} \\
\hline & Years & Months & First & Second & Third & & & & & \\
\hline 1 & 21 & & 16 & 21 & 18 & 43 & 31 & 11 & 13 & 25 \\
\hline 2 & 25 & & 13 & 10 & 13 & 30 & 24 & 3 & 8 & 28 \\
\hline 3 & 24 & & 14 & 20 & 17 & 33 & 21 & 5 & 8 & 28 \\
\hline 4 & 22 & & 19 & 16 & 15 & 38 & 28 & 13 & 8 & 22 \\
\hline 5 & 21 & & 15 & 20 & 20 & 37 & 20 & 12 & 11 & 21 \\
\hline Mean & & & 15.4 & 17.4 & 16.6 & 36.2 & 24.8 & 8.8 & 9.6 & 24.8 \\
\hline 6 & 5 & 1 & 15 & 21 & 21 & 46 & 30 & 3 & 7 & 43 \\
\hline 7 & 5 & 1 & 18 & 21 & 17 & 40 & 21 & 8 & 23 & 46 \\
\hline 8 & 5 & 1 & 25 & 22 & & 50 & 28 & 13 & 22 & 38 \\
\hline 9 & 5 & 0 & 17 & 18 & 17 & 41 & 28 & 18 & 15 & 28 \\
\hline Mean & & & 18.8 & 20 & 18.3 & 44 & 26.8 & 10.5 & 16.8 & 38.8 \\
\hline $\begin{array}{l}10 \\
11\end{array}$ & $\begin{array}{l}4 \\
4\end{array}$ & $\begin{array}{l}1 \\
0\end{array}$ & $\begin{array}{l}18 \\
20\end{array}$ & $\begin{array}{l}19 \\
18\end{array}$ & & $\begin{array}{l}38 \\
40\end{array}$ & $\begin{array}{l}20 \\
29\end{array}$ & $\begin{array}{r}18 \\
9\end{array}$ & $\begin{array}{l}14 \\
12\end{array}$ & $\begin{array}{l}31 \\
45\end{array}$ \\
\hline Mean & & & 19 & 18.5 & & 39 & 24.5 & 13.5 & 13 & 38 \\
\hline 12 & 3 & 6 & 20 & & & 42 & 29 & 15 & 12 & 51 \\
\hline
\end{tabular}

response. The procedure continued until there were five more reversals in the intensity of the tone. The threshold value for that run was computed by obtaining the midpoint for each of the last four reversals and then computing the average of these four midpoint levels. The timing sequence began with a 1 -sec pause after a response, a 1 -sec first observation interval, a 750msec pause, and the $1-\sec$ second observation interval. The experimenter gave the child verbal feedback on each trial. The experiment was subject paced in that the procedure did not repeat until the subject responded. If the subject failed to respond, or some other problem arose, then the experimenter could skip on to the next trial and the previous trial's results would not be used in the calculation of threshold. The entire procedure was controlled by a PDP-8/e computer.

The subject's thresholds were obtained for each frequency. The frequencies were presented in random order, except that the $1,000-\mathrm{Hz}$ tone was always presented first, fourth, and eighth. Trial-by-trial results and the total time to estimate the threshold at each frequency were stored.

\section{Results and Discussion}

Stable results were obtained from all five of the adults, four of the five 5-year-olds, two of the five 4-year-olds, and only one 3-year-old. The results from these successful tests are shown in Table 1. The average time to estimate threshold at each frequency was $3 \mathrm{~min}$ for the adults and $4 \mathrm{~min} 35 \mathrm{sec}$ for the seven children.

Table 2

Thresholds in Decibels SPL for 5-Year-Olds, Using the 2AFC Adaptive Psychophysical Procedure for Experiment 1

\begin{tabular}{cccccc}
\hline & \multicolumn{2}{c}{ Age } & & & \\
\cline { 2 - 5 } Subject & Years & Months & $250 \mathrm{~Hz}$ & $1,000 \mathrm{~Hz}$ & $4,000 \mathrm{~Hz}$ \\
\hline 1 & 5 & 3 & 30 & 14 & 8 \\
2 & 5 & 4 & 36 & 16 & 13 \\
3 & 5 & 2 & 35 & 18 & 9 \\
4 & 5 & 6 & 38 & 17 & 11 \\
5 & 5 & 3 & 37 & 15 & 7 \\
6 & 5 & 0 & 32 & 12 & 16 \\
\hline
\end{tabular}

The technique in this form did not enable us to successfully test all of the subjects, but the results from those tested were within $5-25 \mathrm{~dB}$ of the American National Standard Institute (ANSI) (1969) thresholds.

The major problem with the $2 \mathrm{AFC}$ adaptive procedure was in obtaining usable data from the 3 - and 4-year-olds. The procedure appeared to work well for the 5-year-olds. Table 2 shows the results from six additional 5-year-olds. Their thresholds were estimated at $250,1,000$, and $4,000 \mathrm{~Hz}$, using the procedure described in the Method section of Experiment $1 \mathrm{~A}$.

\section{EXPERIMENT $1 \mathrm{~B}$ (PILOT STUDY)}

Since we were interested in obtaining behavioral thresholds of audibility at the youngest ages possible, and since we had some minor success with the adaptive procedure, we used 10 3-year-olds in a pilot study to determine which variations of the method might yield greater success. The major problem was that the younger children exhibited extreme interval biases in the 2AFC tasks. That is, most of the 3-year-olds were willing to say, "Yes, I heard the tone," or "No, I did not hear the tone," but they were not willing to choose one of two possible intervals that contained the tone. In most cases, the younger children simply said one of the two intervals all of the time, except when the stimulus level was very high. That is, when there was any uncertainty, the young child simply indicated whether the sound came on when, for example, the cow picture was lit (Interval 1, perhaps), or when a horse picture was illuminated (Interval 2), by always replying, "The cow said it." With this knowledge, and the additional experience gained from the pilot study, a single-interval procedure was tried on another set of subjects. 


\section{EXPERIMENT 2}

\section{Method}

Subjects. Ten 3-year-olds, five 4-year-olds, five 5-year-olds, and five adults were tested.

Stimuli. The signal was a train of $250-\mathrm{msec}$ tone bursts presented with a $50 \%$ duty cycle. Each burst was presented with a $10-\mathrm{msec}$ rise-decay time. Two replications at $1,000 \mathrm{~Hz}$ and frequencies of $250,500,2,000,4,000$, and $8,000 \mathrm{~Hz}$ were used. The stimuli were presented to the right ear of each subject through TDH-39 headphones.

Procedure. In these tests, the train of tone bursts was on continuously, except during an "observation interval," during which the train of tone bursts either remained on or was not presented. Whether or not the train of tone bursts was present during the observation interval was determined randomly, with the constraint that runs of four or more of one type of trial (tone bursts or no stimulus presentation) were not allowed. A light marked the observation interval and the subject was asked if he or she heard the stimulus. In most cases, the stimulus was labeled as a bird, dog, cat, or some other object by the child at the first of the experimental session, and the question was, "Do you hear the bird or cat, etc.?" The experimenter, in some cases the mother, pushed a button signifying a "yes" answer by the child and another button for "no."

The stimulus intensity was $60 \mathrm{~dB}$ SPL at the beginning of the test. After each two correct responses, either saying "yes" when the stimulus was presented or "no" when it was not, the level was decreased by $8 \mathrm{~dB}$ until the first incorrect response. Following the first incorrect response, the level was decreased by $4 \mathrm{~dB}$ after each two successive correct responses and was increased by $4 \mathrm{~dB}$ after any incorrect response. The test was completed after five more reversals in the level of the stimulus. Threshold for a test was computed by averaging the midpoint intensities over the last four reversals of stimulus level.

For each subject, the order in which the six frequencies were presented was random, except that the $1,000-\mathrm{Hz}$ sinusoid was presented first and last.

An example of a test run is shown in Figure 1, and the procedure for determining threshold is indicated. Also shown in Figure 1 is a way to estimate percent correct $[P(C)]$ for stimulus intensities above and below the estimated threshold, that is, a way to estimate a psychometric function. This will be explained in more detail in the Results and Discussion section.

In addition to the constraints imposed on the random order
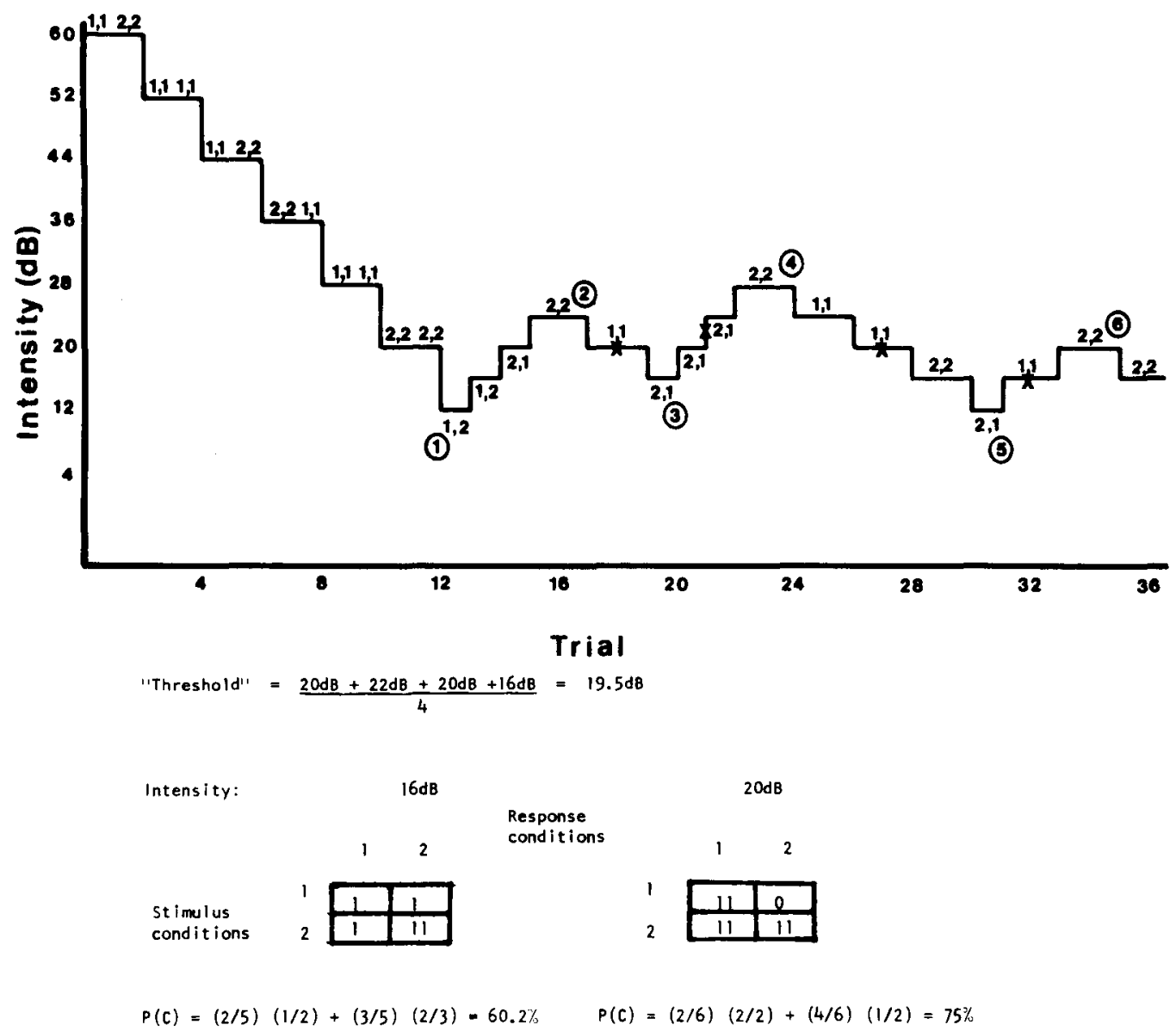

Figure 1. An example of one run of the adaptive psychophysical task is shown. The way in which the estimates threshold and $P(C)$ are determined at intensities above and below the threshold intensity are also indicated. The intensity of the tone is plotted on the abscissa and the trial on the ordinate. The numbers 1 and 2 correspond to the stimulus ( 1 means a signal was presented, 2 means no signal was presented) and response (1 means the subject said "yes," 2 means the subject said "no"). The circled numbers indicate a reversal. The " $x$ " indicates the threshold estimated for each reversal. Below, the four local thresholds are averaged to compute the estimated threshold (19.5 dB) for this run. At an intensity of 16 and $20 \mathrm{~dB}$, there were enough conditions to estimate a value of $P(C)$ from the stimulus-response tables shown below. 
Table 3

Thresholds in Decibels SPL for Various Frequencies and Age Groups

\begin{tabular}{|c|c|c|c|c|c|c|c|c|c|}
\hline \multirow[b]{2}{*}{ Subject } & \multicolumn{2}{|c|}{ Age } & \multicolumn{2}{|c|}{$1,000 \mathrm{~Hz}$} & \multirow[b]{2}{*}{$250 \mathrm{~Hz}$} & \multirow[b]{2}{*}{$500 \mathrm{~Hz}$} & \multirow[b]{2}{*}{$2,000 \mathrm{~Hz}$} & \multirow[b]{2}{*}{$4,000 \mathrm{~Hz}$} & \multirow[b]{2}{*}{$8,000 \mathrm{~Hz}$} \\
\hline & Years & Months & First & Second & & & & & \\
\hline 1 & 3 & 0 & 21 & 23 & 39 & 29 & 18 & 21 & 29 \\
\hline 2 & 3 & 2 & 18 & 12 & 41 & 31 & 21 & 23 & 31 \\
\hline 3 & 3 & 0 & 15 & 22 & 33 & 26 & 23 & 24 & 36 \\
\hline 4 & 3 & 4 & 22 & 25 & 36 & 20 & 19 & 19 & 28 \\
\hline 5 & 3 & 6 & 16 & 15 & 36 & 23 & 17 & 18 & 30 \\
\hline 6 & 3 & 3 & 23 & 23 & 41 & 29 & 15 & 22 & 29 \\
\hline 7 & 3 & 6 & 17 & 19 & 33 & 27 & 13 & 25 & 29 \\
\hline 8 & 3 & 6 & 15 & 20 & 32 & 28 & 21 & 21 & 35 \\
\hline 9 & 3 & 3 & 20 & 21 & 30 & 23 & 18 & 23 & 27 \\
\hline Mean & & & 18.6 & 20.0 & 35.7 & 26.2 & 18.3 & 21.8 & 30.4 \\
\hline 1 & 4 & 6 & 18 & 23 & 40 & 23 & 16 & 20 & 30 \\
\hline 2 & 4 & 3 & 19 & 23 & 35 & 21 & 18 & 25 & 32 \\
\hline 3 & 4 & 2 & 22 & 16 & 39 & 18 & 24 & 23 & 35 \\
\hline 4 & 4 & 8 & 14 & 18 & 33 & 25 & 19 & 24 & 29 \\
\hline 5 & 4 & 6 & 20 & 21 & 35 & 21 & 18 & 16 & 21 \\
\hline Mean & & & 18.6 & 20.2 & 36.4 & 21.6 & 19 & 21.6 & 29.4 \\
\hline 1 & 5 & 0 & 19 & 25 & 37 & 26 & 18 & 19 & 28 \\
\hline 2 & 5 & 6 & 17 & 16 & 33 & 23 & 17 & 23 & 30 \\
\hline 3 & 5 & 3 & 21 & 24 & 31 & 28 & 20 & 21 & 23 \\
\hline 4 & 5 & 3 & 22 & 21 & 29 & 25 & 19 & 24 & 28 \\
\hline 5 & 5 & 6 & 18 & 20 & 36 & 26 & 22 & 26 & 29 \\
\hline Mean & & & 19.4 & 21.2 & 33.2 & 25.6 & 19.2 & 22.6 & 27.6 \\
\hline 1 & 21 & & 16 & 13 & 26 & 20 & 18 & 15 & 25 \\
\hline 2 & 26 & & 18 & 17 & 30 & 25 & 17 & 21 & 27 \\
\hline 3 & 23 & & 15 & 14 & 31 & 22 & 16 & 20 & 31 \\
\hline 4 & 24 & & 17 & 19 & 29 & 18 & 17 & 19 & 23 \\
\hline 5 & 25 & & 18 & 20 & 32 & 19 & 20 & 20 & 29 \\
\hline Mean & & & 16.8 & 16.6 & 29.6 & 20.8 & 17.6 & 19 & 27 \\
\hline
\end{tabular}

of signal presentation, other constraints or options were included. A trial could be cancelled at any time, and the test continued without the results of that trial being considered in the threshold determination. If more than 60 trials were run, the experiment was terminated. If the child responded 13 or more times in a row with one response, then the experiment was terminated. Since no runs of more than four of one type were allowed for the stimulus, 13 responses of one type indicated an "extreme" bias toward that response.

\section{Results and Discussion}

The sound pressure level (SPL) thresholds of audibility in decibels for each subject successfully completing the entire procedure are shown in Table 3; the average thresholds for each group of subjects are plotted in Figure 2 and compared to the relevant thresholds from the ANSI (1969) standard. Figure 3 describes estimates of the psychometric functions that can be derived from the data obtained in the adaptive procedure. The data in Figure 3 were obtained by first determining, for certain stimulus intensities in each run of the experiment, the $P(C)$ responses for that intensity (see Figure 1). The computer kept track of the stimulus and response condition for each trial, that is, for each stimulus intensity presented, and then for certain conditions computed $\mathrm{P}(\mathrm{C})$ by $\mathrm{P}(\mathrm{C})=\mathrm{P}(\mathrm{S}) \mathrm{P}($ Hit $)+\mathrm{P}(\mathrm{N}) \mathrm{P}($ Correct Rejection $)$, where $P(S)$ is the proportion of the signal presentations,
$\mathrm{P}(\mathrm{N})$ the proportion of no signal presentations, $\mathrm{P}(\mathrm{Hit})$ the proportion of times the subject correctly detected the presence of the signal, and $\mathrm{P}$ (Correct Rejection) the proportion of times the subject correctly detected the absence of the stimulus. $P(C)$ was computed only for those intensities presented four or more times during an experimental run and when $\mathrm{P}(\mathrm{Hit})$ and $\mathrm{P}$ (Correct Rejection) did not both equal 1.0 or 0.0 . Each time these conditions were met, $P(C)$ for that intensity was

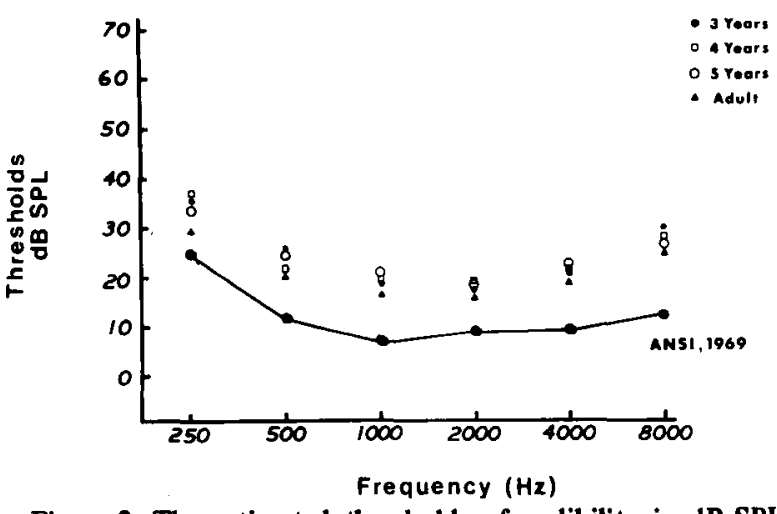

Figure 2. The estimated thresholds of audibility in $\mathrm{AB}$ SPL for the four age groups are shown and compared to the ANSI (1969) thresholds. 


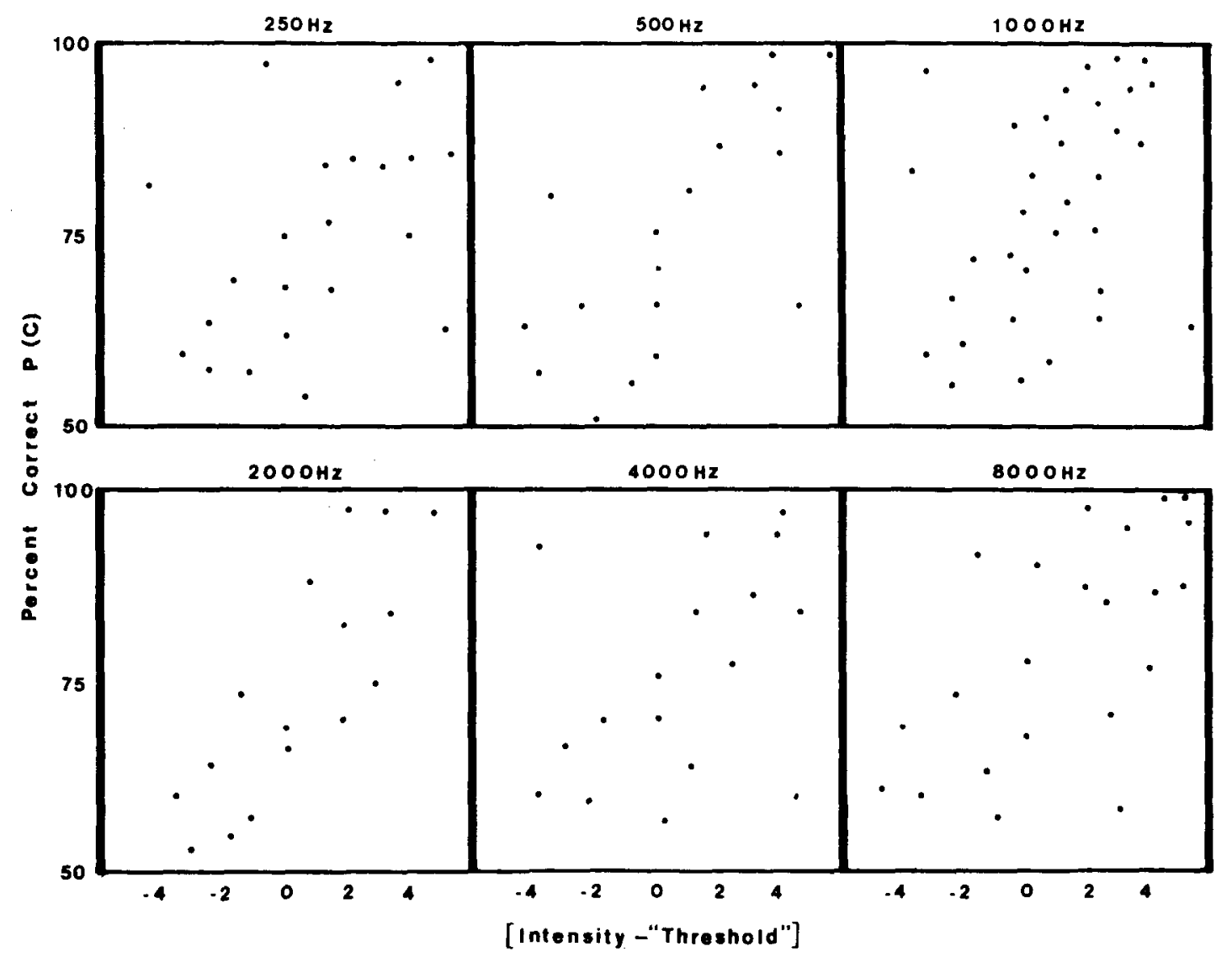

(dB)

Figure 3. The estimated psychometric functions obtained across the 19 children for each frequency tested. The functions are "normalized" to the estimated threshold by a procedure explained in the text.

computed. Figure 3 was obtained by taking each of these intensities and subtracting the estimated threshold to obtain the abscissa value. The ordinate values were the $\mathrm{P}(\mathrm{C}) \mathrm{s}$ for the intensity used. That is, the psychometric functions are normalized to the estimated threshold values. Since there were only a few points (sometimes none) estimated per condition, Figure 3 represents the results for all 19 children for each frequency.

Table 4 indicates estimates of the response bias the subjects showed toward saying, "Yes, I detected the signal," or "No, I did not detect the signal." The bias is tabulated as $\log \mathrm{P}(\mathrm{Y}) / \mathrm{P}(\mathrm{N}) ; \mathrm{P}(\mathrm{Y})$ is the proportion of "yes" responses, and $\mathrm{P}(\mathrm{N})$ is the proportion of "no" responses following the first reversal in each condition. ${ }^{2}$ Thus $\log \mathrm{P}(\mathrm{Y}) / \mathrm{P}(\mathrm{N})$ of .3 means the subject said "yes" twice as often as "no," and $\log \mathrm{P}(\mathrm{Y}) / \mathrm{P}(\mathrm{N})$ of -.3 means the subject said "no" twice as often as "yes." The results of Table 4 indicate that the children had a very small bias toward saying "no," while the adults had a slight tendency to say "yes." The bias was, in most cases, so small that the error in estimating threshold was probably 1-2 $\mathrm{dB}$, compared to a method that may have generated no bias or had a bias-independent measure of performance been used.
Five tests are available for evaluating this method of estimating thresholds of audibility in children: the mean threshold estimates, the psychometric function, the response bias, the within-subjects variability (at $1,000 \mathrm{~Hz}$ ), and the between-subjects variability. These tests can be made on the data obtained from the children and compared to other results, or the children's results can be compared to those of the adults.

In general, there are no systematic differences among the three age groups of the children in terms of the mean thresholds. However, the adults tended to yield thresholds slightly lower than the children's, although the differences are within the range of variability typically obtained in estimates of the thresholds of audibility (see Watson et al., 1972). Thresholds were between 5 and $12 \mathrm{~dB}$ greater than those for the comparable thresholds defined in the ANSI (1969) standard. Given the 4-dB step size of attenuation, one would expect a somewhat higher estimation of threshold than for procedures using smaller attenuation step sizes. According to the results of Watson et al. (1972), these threshold values would have yielded d' values of 4.0 or more for highly trained adult observers in a nonadaptive, two-alternative, forced-choice task. ${ }^{3}$

The data for the psychometric functions shown in 
Table 4

Response Bias or $\log P(Y) / P(N)$ for Each Subject and for Each Signal Frequency

\begin{tabular}{|c|c|c|c|c|c|c|}
\hline \multirow[b]{2}{*}{ Subject } & \multicolumn{6}{|c|}{ Signal Frequency (in Hertz) } \\
\hline & 250 & 500 & 1,000 & 2,000 & 4,000 & 8,000 \\
\hline \multicolumn{7}{|c|}{ 3-Year-Olds } \\
\hline $\begin{array}{l}1 \\
2 \\
3 \\
4 \\
5 \\
6 \\
7 \\
8 \\
9\end{array}$ & $\begin{array}{r}-.03 \\
-.18 \\
-.03 \\
+.06 \\
-.01 \\
+.01 \\
0.00 \\
-.04 \\
-.18\end{array}$ & $\begin{array}{r}-.13 \\
-.08 \\
+.13 \\
-.20 \\
-.08 \\
-.01 \\
-.04 \\
+.09 \\
-.26\end{array}$ & $\begin{array}{r}-.06 \\
-.13 \\
-.03 \\
0.00 \\
-.07 \\
+.03 \\
+.07 \\
-.09 \\
-.17\end{array}$ & $\begin{array}{r}-.13 \\
+.03 \\
-.23 \\
-.02 \\
-.18 \\
-.04 \\
-.09 \\
+.11 \\
-.23\end{array}$ & $\begin{array}{r}-.06 \\
-.18 \\
-.20 \\
-.13 \\
-.26 \\
+.01 \\
+.03 \\
+.08 \\
-.16\end{array}$ & $\begin{array}{r}-.09 \\
-.11 \\
-.14 \\
-.06 \\
-.18 \\
+.06 \\
+.11 \\
+.08 \\
+.03\end{array}$ \\
\hline \multicolumn{7}{|c|}{ 4-Year-Olds } \\
\hline $\begin{array}{l}1 \\
2 \\
3 \\
4 \\
5\end{array}$ & $\begin{array}{r}-.13 \\
+.04 \\
-.20 \\
-.20 \\
-.01\end{array}$ & $\begin{array}{r}-.06 \\
+.08 \\
-.11 \\
+.09 \\
0.00\end{array}$ & $\begin{array}{l}-.11 \\
+.13 \\
-.18 \\
-.11 \\
-.06\end{array}$ & $\begin{array}{r}-.08 \\
+.09 \\
-.02 \\
-.21 \\
-.10\end{array}$ & $\begin{array}{r}-.20 \\
+.16 \\
-.17 \\
-.06 \\
-.05\end{array}$ & $\begin{array}{l}-.14 \\
-.01 \\
-.06 \\
-.04 \\
-.18\end{array}$ \\
\hline \multicolumn{7}{|c|}{ 5-Year-Olds } \\
\hline $\begin{array}{l}1 \\
2 \\
3 \\
4 \\
5\end{array}$ & $\begin{array}{r}-.03 \\
-.09 \\
-.18 \\
+.11 \\
-.16\end{array}$ & $\begin{array}{r}+.08 \\
-.11 \\
-.03 \\
+.02 \\
-.05\end{array}$ & $\begin{array}{r}+.11 \\
-.03 \\
-.03 \\
+.21 \\
-.06\end{array}$ & $\begin{array}{r}+.13 \\
-.08 \\
-.17 \\
+.13 \\
-.13\end{array}$ & $\begin{array}{r}+.16 \\
-.20 \\
-.07 \\
+.03 \\
-.16\end{array}$ & $\begin{array}{r}+.06 \\
-.23 \\
-.09 \\
+.01 \\
-.07\end{array}$ \\
\hline \multicolumn{7}{|c|}{ Adults } \\
\hline $\begin{array}{l}1 \\
2 \\
3 \\
4 \\
5\end{array}$ & $\begin{array}{r}0.00 \\
+.01 \\
+.04 \\
+.05 \\
+.13\end{array}$ & $\begin{array}{r}+.03 \\
+.09 \\
+.01 \\
0.00 \\
+.11\end{array}$ & $\begin{array}{r}-.02 \\
0.00 \\
+.06 \\
+.10 \\
+.03\end{array}$ & $\begin{array}{r}+.01 \\
+.03 \\
+.08 \\
+.09 \\
0.00\end{array}$ & $\begin{array}{l}+.08 \\
+.10 \\
+.02 \\
0.00 \\
+.03\end{array}$ & $\begin{array}{r}-.01 \\
-.03 \\
+.09 \\
-.01 \\
+.01\end{array}$ \\
\hline
\end{tabular}

Note-P(Y) is the proportion of "yes" responses; $P(N)$ is the proportion of "no" responses.

Figure 3 indicate that a range of approximately 6 to $16 \mathrm{~dB}$ in stimulus intensity would change the subject's $\mathrm{P}(\mathrm{C})$ responses from chance to $100 \%$. This estimate is similar to many obtained in threshold experiments (ranges of 6 to $10 \mathrm{~dB}$ have been reported by Egan, Linder, and McFadden, 1966, and by Green and Swets, 1974), but larger than those reported by Watson et al. (1972) ( 3 to $6 \mathrm{~dB}$ ). However, given the extremely small number of trials (four to nine) used to estimate a point on the psychometric function, the expected variability is extremely large. Therefore, any accurate estimate of these slopes is not possible.

The standard deviations of the thresholds of audibility across subjects for the children ranged from $2.1 \mathrm{~dB}$ for the $2,000-\mathrm{Hz}$ conditions to $3.7 \mathrm{~dB}$ for the $8,000-\mathrm{Hz}$ condition, and for the adults from $1.4 \mathrm{~dB}$ for the $2,000-\mathrm{Hz}$ condition to $2.8 \mathrm{~dB}$ for the $8,000-\mathrm{Hz}$ condition. The range of differences between the two estimates of threshold at $1,000 \mathrm{~Hz}$ was from 0 to $7 \mathrm{~dB}$ for the children (with an average difference of $3.2 \mathrm{~dB}$ ) and from 1 to $3 \mathrm{~dB}$ for the adults (with an average difference of $1.8 \mathrm{~dB}$ ). Thus, the three estimates of variability (slope of the psychometric function, standard deviation of thresholds across subjects, and difference in thresholds for the two repetitions at $1,000 \mathrm{~Hz}$ ) all indicate that, for children less than 6 years of age, a 3- to $16-\mathrm{dB}$ change in threshold is the type of variability that one might expect from this procedure for both within- and between-subjects variability. The variability appears to be somewhat lower for adults than for children. These estimates are larger than those reported by Watson et al. (1972) and closer to those obtained by other investigators (Egan et al., 1966; Green \& Swets, 1974).

The method was successfully used on all except one of the 3-year-old subjects in Experiment 2. The 3-yearold girl refused to wear headphones. The child returned to the laboratory 1 week later, when we tested audibility at 250 and $1,000 \mathrm{~Hz}$ by presenting the tones through an ARX-3 loudspeaker. Thresholds were estimated successfully, but we were unable to calibrate the listening environment to our satisfaction, so her results are not included in Table 3 or Figure 1. The difference between 250 and $1,000 \mathrm{~Hz}$ was $25 \mathrm{~dB}$, which is consistent with the results from the other 3-year-olds, even though a loudspeaker was used instead of earphones.

The average time to obtain the six thresholds was $21.6 \mathrm{~min}$. The adults required $18.3 \mathrm{~min}$, and the 3-yearolds, $27.2 \mathrm{~min}$. Thus, it takes approximately 3.5 to 4 min to test at each frequency.

The operations are straightforward. The procedure can be administered manually by having someone keep track of the correct and incorrect responses, rather than by computer. Simple logic systems could implement the procedure. The only major expense is for digital or program control of signal level.

Both procedures were designed to be as objective and automatic as possible. But there is still a significant requirement for experimenter-child interaction and rapport. Children often begin to lose interest in the "game" or play another "game." The experimenter must be aware of these changes in order to keep the child participating in the experiment. Some of the built-in contingencies help the experimenter to verify if a child is not participating appropriately. In most instances, this insight has to be learned by the experimenter.

Levitt (1971) outlines the basic assumptions and principles needed to use the adaptive psychophysical procedures to estimate thresholds. The most critical assumption is that "the expected proportion of positive responses is a monotonic function of stimulus level (at least over the region in which observations are made)" (Levitt, 1971, p. 468). The other matter of importance is the procedure used to estimate the parameter of interest (threshold in this case). The data of Figure 3 and the assumptions normally used to test thresholds of audibility indicate that the first assumption is valid for the procedures used in this study. Given our measures of variability and comparisons of results 
with other studies, the threshold-estimation procedure appears accurate.

Of course, response bias can affect measures of performance (see McFadden, 1970) and the thresholds estimated by adaptive procedures (see Creelman \& Taylor, 1969). A 2AFC procedure is usually preferred over the single-interval method, since subjects do not typically have an interval bias in $2 \mathrm{AFC}$ tasks, whereas subjects often do display a "yes-no" bias in singleinterval procedures (Robinson \& Watson, 1972). When the false-alarm rate is not known due to a response bias, then the adaptive procedure can lead to large errors in threshold estimates, since for any one stimulus intensity only a small number of observations are used to estimate the false-alarm rate (see Creelman \& Taylor, 1969). The typical use of response bias in $2 \mathrm{AFC}$ and single-interval tasks was not always obtained for the procedures used in this study. The younger children displayed extreme interval biases in the $2 \mathrm{AFC}$ procedure, making it impossible to use it to estimate their thresholds. As the data of Table 4 indicate, the "yes-no" response bias is small; therefore, accurate estimation of the false-alarm rate is not as important as if there had been a response bias. Therefore, for the subjects of Experiment 2, it appears as if the single-interval procedure allowed for a reasonable estimate of the thresholds of audibility. Given the problem of response criterion in singleinterval procedures, the procedure is only valid when the response bias of the subjects is known (ideally, when there is no response bias). For 5-year-olds, the preferred 2AFC method successfully estimates thresholds of audibility.

\section{REFERENCES}

American National Standard Institute. Specifications for audiometers (S 3.6). New York: Author, 1969.

Creelman, C. D., \& Taylor, M. M. Some pitfalls in adaptive testing: Comments on "Temporal integration and periodicity pitch." Journal of the Acoustical Society of America, 1969. 46, 1581-1583.
Egan, J. P., Linder, W. A., \& McFadden, D. Masking level differences and the form of the psychometric function. Perception \& Psychophysics, 1966, 6, 209-215.

Green. D. M., \& Swets, J. A. Signal detection theory and psychophysics. New York: Kriegar, 1974.

Jesteadt, W., WIER, C. C., \& GREen, D. M. Intensity discrimination as a function of frequency and sensation level. Journal of the Acoustical Society of America, 1977, 61, 169-178.

LevitT, H. Transformed up-down methods in psychoacoustics. Journal of the Acoustical Society of A merica, 1971, 49, 467-477.

MCFADDEN, D. Three computational versions of proportion correct for use in forced-choice experiments. Perception \& Psychophysics, 1970, 8, 336-393.

Rosinson, D. E., \& W WTSOn, C. S. Psychophysical methods in modern psychoacoustics. In J. V. Tobias (Ed.), Foundations of modern auditory theory (Vol. 2). New York: Academic Press, 1972.

TAYlor, M. M., \& Creelman, C. D. PEST: Efficient estimates on probability functions. Journal of the Acoustical Society of America, 1967, 41, 782-787.

Watson, C. C., Franks, J. R., \& Hood, D. C. Detection of tones in the absence of external masking noise 1: Effects of signal intensity and signal frequency. Journal of the Acoustical Society of America, 1972, 52, 633-643.

Yost, W. A. Frequency selectivity using tonal-temporal masking: Diotic vs. dichotic masking. Perception \& Psychophysics. 1975, 18, 423-427.

\section{NOTES}

1. All intensities refer to the level measured in a B\&K 6-cc coupler (Model 4152) with a B\&K condenser microphone (Model 4144) and are expressed in decibels relative to $.0002 \mathrm{dynes} / \mathrm{cm}^{2}$ or $\mathrm{dB}$ SPL.

2. Prior to the first reversal, the subjects were always correct; $\mathrm{P}(\mathrm{Y}) / \mathrm{P}(\mathrm{N})$ is therefore simply the ratio of $\mathrm{P}(\mathrm{S}) / \mathrm{P}(\mathrm{N})$. Therefore, $\log P(Y) / P(N)$ was not estimated for trials prior to the first reversal. Also, due to the constraints imposed on the random order of the stimulus presentation, $P(S) / P(N)$ is very nearly always 1 throughout any run of the procedure. Therefore, $P(Y) / P(N)$ provides a reasonably accurate distributionindependent estimate of the subject's response bias over any one run of the procedure.

3. In the present experiment, a $d^{\prime}$ of 4.0 would indicate a $P(C)$ of approximately $97 \%$ or higher.

(Received for publication March 15, 1978; revision accepted June 8,1978 .) 